\title{
Introduction to special session on microscopy for Science, Technology, Engineering and Math (STEM) educators
}

\section{Michael Postek, Mary Satterfield, Bradley Damazo, Robert Gordon}

Michael T. Postek, Mary Satterfield, Bradley Damazo, Robert Gordon, "Introduction to special session on microscopy for Science, Technology, Engineering and Math (STEM) educators," Proc. SPIE 8378, Scanning Microscopies 2012: Advanced Microscopy Technologies for Defense, Homeland Security, Forensic, Life, Environmental, and Industrial Sciences, 837817 (2 December 2014); doi: 10.1117/12.2183085

Event: SPIE Defense, Security, and Sensing, 2012, Baltimore, Maryland, United States 


\title{
Introduction to Special Session on Microscopy for Science, Technology, Engineering and Math (STEM) Educators
}

\author{
Michael T Postek, ${ }^{[1]}$ Mary Satterfield,,${ }^{[2]}$ Bradley Damazo, ${ }^{[1]}$ and Robert Gordon ${ }^{[3]}$ \\ Semiconductor and Dimensional Metrology Division ${ }^{[1]}$ \\ Biochemical Science Division ${ }^{[2]}$ \\ National Institute of Standards and Technology, Gaithersburg, MD 20899, ${ }^{[1,2]}$ \\ and \\ Hitachi High Technologies America, Inc., Pleasanton, CA 94588 [3]
}

\begin{abstract}
The future of our nation hinges on our ability to prepare our next generation to be innovators in science, technology, engineering and math (STEM). Excitement for STEM must begin at the earliest stages of our education process. Yet, today far too few of our students are prepared for the challenges ahead. Several initiatives are trying to change this situation. "Microscopy for STEM Educators" was an initiative that demonstrated the value of incorporating microscopy into STEM education. Several notable invited speakers discussed their successful programs implementing microscopy in STEM education in order to foster student interest and excitement. A hands-on session with table-top scanning electron microscopes was held at the end of the presentations and the attendees were encouraged to bring samples of interest and operate the instruments. This paper outlines some of the accomplishments and goals of this session.
\end{abstract}

Keywords: STEM, science, technology, engineering, math, microscopy, SEM, scanning electron microscope, NNI, nanotechnology

\subsection{INTRODUCTION}

The future of our nation hinges on our ability to prepare our next generation to be innovators in science, technology, engineering and math (STEM). This is especially true with the U.S. commitment of nearly \$20B over the past $10+$ years in nanotechnology [www.nano.gov] and the resulting nanomanufacturing that will be developed to assure that this investment bears fruit. A well-trained workforce versed in STEM will be in great demand in the near future, but will they be available? This is a concern of both the business and scientific community.

A number of Federal and State Government programs are geared to foster the interest in STEM. For example the National Science Board report "Preparing the Next Generation of STEM Innovators: Identifying and Developing Our Nation's Human Capital" [3] contains a series of policy actions, a research agenda, and a number of key recommendations detailing how our Nation might foster the identification and development of future STEM innovators. This all begins with exciting the STEM teachers with technology that can be brought into the classroom, which can in turn excite the students to excel. In keeping with this philosophy, a special session entitled "Microscopy for STEM Educators" was held at the SPIE SCANNING Microscopies 2012 meeting as part of the 2012 SPIE Defense Security+Sensing Symposium.

Excitement for STEM must begin in the earliest stages of our education process because far too few of our students are prepared for the challenges ahead. One mechanism for doing this is through microscopy. Figures 1 and 2 show the wonderment expressed by a group of students at one scanning electron microscopy forum presented at the California Science Center, Los Angeles, CA as they crowd around the microscope and view the image on the computer screen (Figure 1) and as they load the specimen into the microscope specimen chamber (Figure 2). Microscopy provides a picture window into an exciting, but typically unseen and often unimagined world. The scanning electron microscope (SEM) is an instrument that can allow the students to enter into this world by producing startling images of the world surrounding us at higher magnification and resolution than the unaided eye or even optical microscopes. Unfortunately, until recently, the SEM was

Scanning Microscopies 2012: Advanced Microscopy Technologies for Defense, Homeland Security, Forensic, Life, Environmental, and Industrial Sciences, edited by Michael T. Postek, Dale E. Newbury, S. Frank Platek, David C. Joy, Tim K. Maugel, Proc. of SPIE Vol. 8378, 837817 - @ 2012 SPIE · CCC code: 0277-786X/12/\$18 · doi: 10.1117/12.2183085

Proc. of SPIE Vol. 8378 837817-1 
a very large, expensive research instrument relegated to laboratories at universities or industry. Today, numerous models of SEMs remain relatively expensive and imposing research instruments, but also a new class of much smaller, mobile and less expensive table-top type instruments are available that can easily be transported into the classroom.

The special session "Microscopy for STEM Educators" was a general interest forum held with several notable invited speakers who discussed their successful programs implementing microscopy in STEM education. STEM educators were invited from the local vicinity and SPIE provided them with a one-day special registration and full access to the exhibits. In addition, a hands-on session with table-top scanning electron microscopes was held at the end of the presentations and the attendees were encouraged to bring samples of interest and to actually operate the instruments.

\subsection{Session Presentations}

The session, for STEM teachers, was designed to provide the attendees with a wealth of information regarding the successful incorporation of microscopy into STEM programs. The overall session was comprised of an introduction and five main presentations that provided information, from various application areas to spur the imagination of the teachers and students and make the educators aware of available resources. The presentations were:

2.1 Forensic practice in the field of protection of cultural heritage - Marek Kotrly, Ivana Turkova, Institute of Criminalistics Prague (Czech Republic) provided the real-world applicability of microscopy to the STEM teachers. Crime scene investigation (CSI) is of great interest and microscopy plays a key role in revealing answers to issues covering analysis of objects of art. Microscopy provides a way to examine forgeries and inspect for alteration of historical documents and chronicles.

2.2 Science and art at the nanoscale - Baratunde A. Cola, Georgia Institute of Technology (United States); Kelly Voss, Renee Gaither, Tucker High School (United States); Jamila Cola, Georgia Institute of Technology (United States). This group from the Georgia Institute of Technology NanoEngineered Systems and Transport (NEST) Lab in collaboration with the Georgia Tech Center for Education Integrating Science Mathematics and Computing (CEISMC) described their work with science and art teachers at Tucker High School in DeKalb County Georgia. The SEM allowed the students to visualize and explore the nanostructure of materials that play a role in processes used to convert heat energy to electricity.

2.3 The National Nanotechnology Infrastructure Network's Education and Outreach Programs: understanding size and scale and the tools of nano - Nancy Healy, Georgia Institute of Technology (United States) discussed the National Nanotechnology Infrastructure Network (NNIN) which is an integrated geographically-diverse partnership of 14 university-based laboratories supported by the National Science Foundation. The primary focus of NNIN is to serve as state-of-the-art resource centers for researchers. The NNIN provides extensive education outreach programs for the kindergarten to senior citizen (K-to-gray) population. Dr. Healy shared lessons-learned in helping students understand concepts relating to size and scale as well as how microscopy was incorporated their outreach programs.

2.4 Integrating research and advanced microscopy into the high school curriculum - David Becker, Bergen County Technical Schools (United States). This invited presentation described how the Bergen County Academies, a public magnet high school focused on STEM education, incorporated microscopy into their curriculum. The school is home to the Nano-Structural Imaging Lab (NSIL) where students have access to an SEM, a transmission electron microscope (TEM), and a laser scanning confocal microscope (LSCM).

\subsection{Participating Programs}

There are a number of programs available to the STEM teachers. Two programs of interest are the National Institute of Standards and Technology (NIST) Summer Institute for Middle School Science Teachers and the Change the Equation Program (CTEq): 


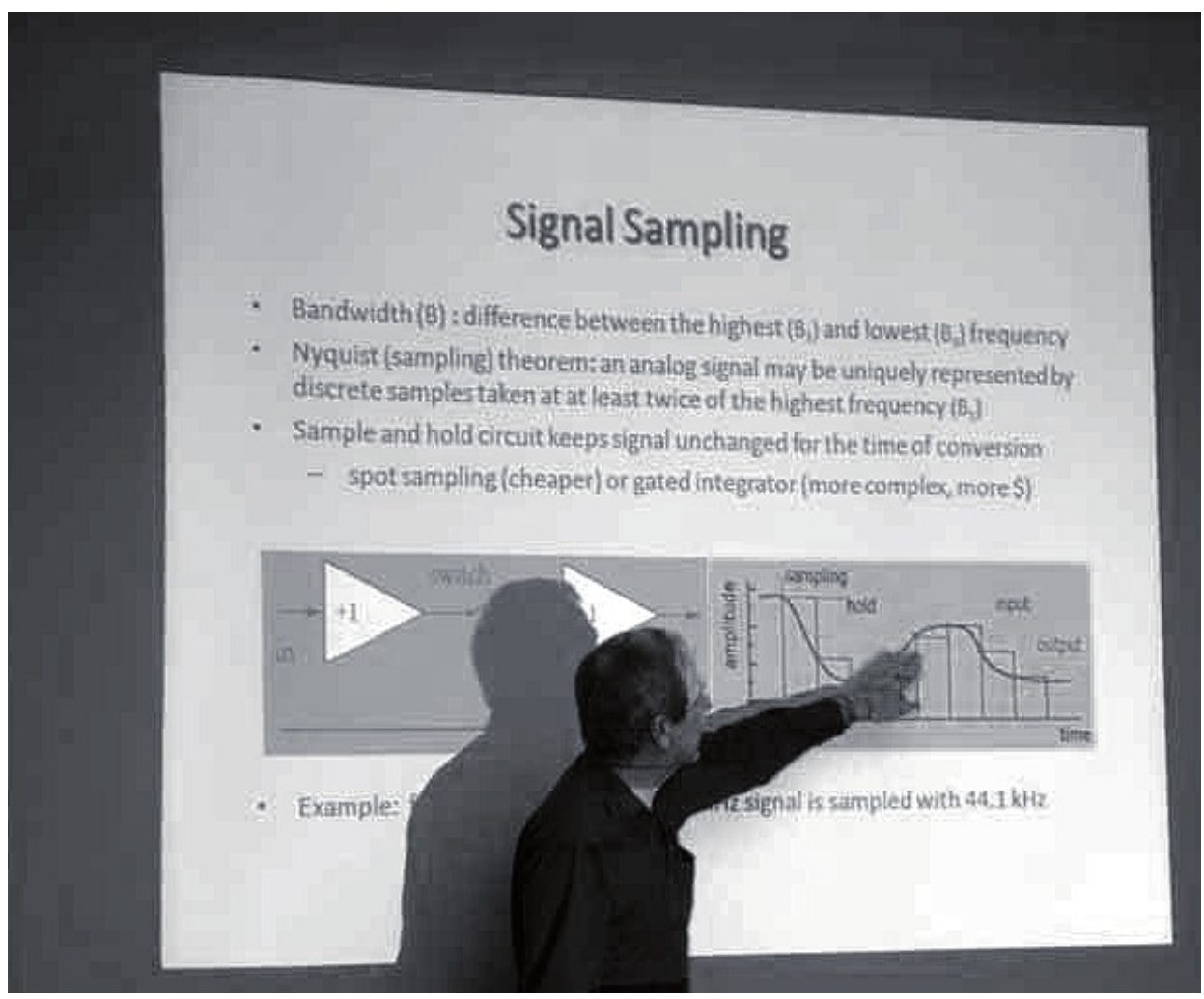

Figure 1. Dr. Andras Vladár lectures on the operation of the scanning electron microscope to middle school teachers during one of the NIST science in the afternoon sessions.

3.1 NIST Summer Institute for Middle School Science Teachers. For the past several years, the Summer Institute for Middle School Science Teachers, a 2 week workshop, has been held on the NIST Gaithersburg Campus. Grants support the attendance by the teachers and in 2011, 20 teachers participated. Started in 2007 as a regional program, teachers from across the country now attend. Last summer's program had teacher participants from Illinois, North Carolina, South Carolina, Virginia, Maryland, and Washington D.C. Over 100 NIST scientists, and staff support the program by giving lectures and leading activities designed to increase teacher understanding of the subjects they teach, visiting with teachers in their laboratories to increase teachers' understanding of how scientific research is performed, and providing a network of scientists and engineers at NIST available for consultation. Further information regarding this program can be found at: http:// nist.gov/iaao/teachlearn/.

3.2 Change the Equation (CTEq). Change the equation was started by five Chief Operating Officers from some of the largest companies in the U.S along with Carnegie Corporation of New York and the Bill \& Melinda Gates Foundation. This is a non-profit, non-partisan CEO-led initiative to help solve America's innovation problem. CTEq is meant to answer the call of President Obama's "Educate to Innovate" campaign to move the U.S. to the top of the pack in science and math education over the next decade. CTEq is interested in improving STEM education for every child, with a particular focus on girls and students of color, who have long been underrepresented in STEM fields. The current membership of CTEq is 110 companies who are working together to connect and align their work to transform STEM learning in the U.S. Further information regarding this program can be found at: http://www.changetheequation.org/.

\subsection{Materials and Methods}

The first prototype SEMs, were built in the 1950's, they were largely constructed from World War II surplus electronics and were large and imposing since this was during the pre-microelectronics era. In the 1960's, the first commercial instruments introduced were quite large, as well. In the early 1970's, initial table top-type instruments were introduced, but performance limitations and flexibility kept them from becoming popular. Recently, with the development of nanoelectronics and 

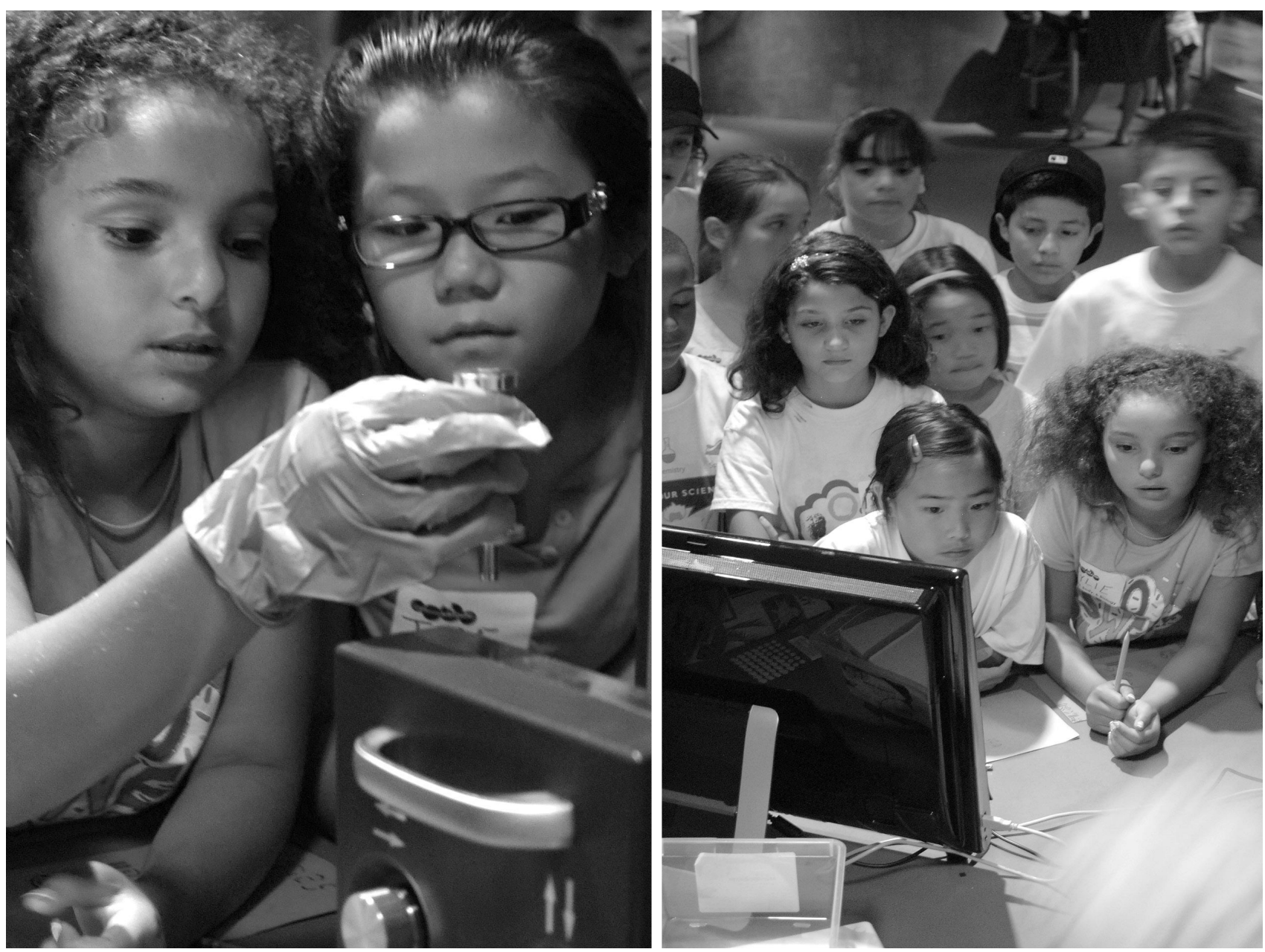

Figure 2 (Left). Grade school students inserting a specimen into the sample chamber of the table-top scanning electron microscope. (Right). Students observing images on the table-top scanning electron microscope at the California Science Center. (Many thanks to Mr. Norberto Oropez, Senior Manager of Public Programs for permission to use the pictures).

the advances it provides, a greater emphasis on smaller more compact microscopes prompted the revival of the table-top instrument. Today, many of the table-top instruments available are small, highly portable, easy to operate, and have performance comparable to many of the earlier laboratory instruments.

4.1 Samples and Instrument. All of the current table-top microscope companies were invited to participate in the "Microscopy for STEM Educators" forum and hands-on session. Several provided instruments. For the purpose of this publication, images from the Hitachi TM 3000 [2] were used. The STEM teachers were encouraged to bring real-world samples of interest. Sample preparation was limited to attachment to the specimen holder (referred to as a "stub") using conductive tape or conductive glue and specimens were typically viewed without any additional metal coating.

\subsection{Results}

A number of micrographs were taken from the array of specimens provided by the teachers and their students. Additional specimens were "captured" from the local environment such as plant leaves and insects. Figure 3 shows a micrograph of a sponge and shows the capture of dirt particles within the pores. Figure 4 shows a portion of the face on the surface of a dime and some of the imperfections due to wear. Figure 5 is the head of a "stink" bug captured in the conference room being used by the seminar and Figure 6 is a micrograph of the insect face-on. 

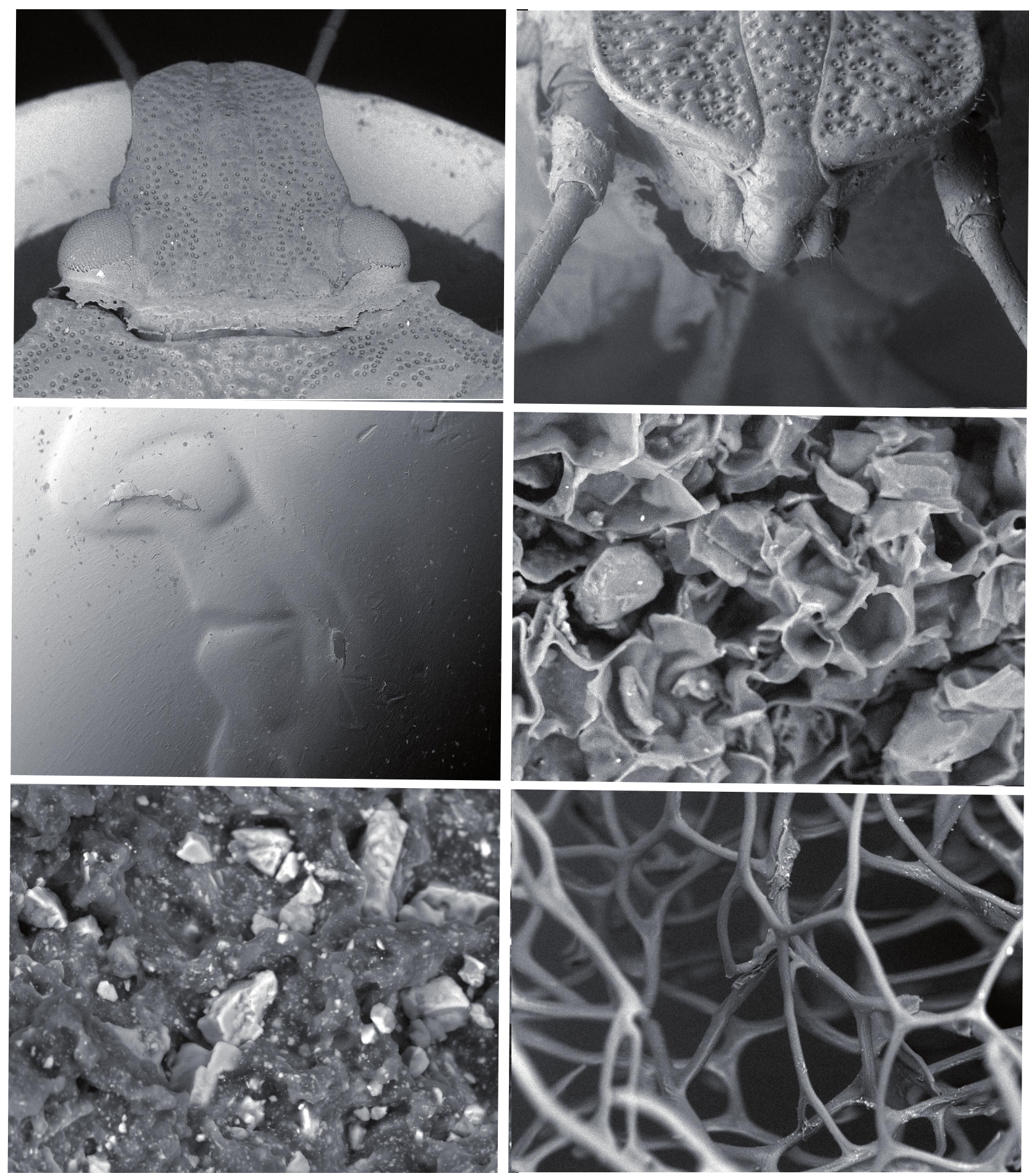

Figures 3. (Top, Left) ) Micrograph of the head of a "stink" bug captured in a conference room being used for a recent middle student teacher's seminar (Field of view $=4 \mathrm{~mm}$ ); (Top, Right) Micrograph of the same insect viewed rotated to view it face-on. (Field of view $=4 \mathrm{~mm}$ ); (Middle, Left) Micrograph of a portion of the face on the surface of a dime showing some of the imperfections due to wear (Field of view $=4 \mathrm{~mm}$ ); (Middle, Right) Micrograph of a piece of cork (Field of view $=165 \mathrm{micrometers}$ ); (Bottom, Left) Micrograph of an eraser (Field of view $=83.5$ micrometers), and (Bottom, Right) Micrograph of an uncoated section of a sponge that shows the capture of dirt particles within the pores (Field of view $=600$ micrometers). 


\subsection{Conclusions}

Programs such as these are crucial in the development of our nation's human capital through our education system. This is an essential building block for future innovation. Currently, the abilities of far too many of America's young men and women go unrecognized and underdeveloped, and, thus, they fail to reach their fullest potential. This represents a huge talent loss for both the individual and society. There are students with high potential from every demographic and from every part of our country, who with hard work and the proper educational opportunities, will form the next generation of science, technology, engineering, and mathematics (STEM) innovators.

\subsection{References}

[1] Contribution of the National Institute of Standards and Technology; not subject to copyright.

[2] Certain commercial equipment is identified in this report to adequately describe the experimental procedure. Such identification does not imply recommendation or endorsement by the National Institute of Standards and Technology, nor does it imply that the equipment identified is necessarily the best available for the purpose.

[3] http://www.nsf.gov/nsb/publications/2010/nsb1033.pdf 